\title{
A Readiness Evaluation of Applying e-Government in the Society: Shall Citizens begin to Use it?
}

\author{
Laith T. Khrais* ${ }^{1}$, Mohammad Awni Mahmoud ${ }^{3}$ \\ Department of Business Administration ${ }^{1}$ \\ Department of MIS $^{3}$ \\ College of Applied Studies and Community Services \\ Imam Abdulrahman Bin Faisal University \\ Dammam, Saudi Arabia ${ }^{1,3}$
}

\author{
Yara M. Abdelwahed ${ }^{2}$ \\ Faculty of Commerce \\ Menoufia University, Menoufia, Egypt
}

\begin{abstract}
As people are in the era of the web, most of the society is using networks in their daily task, governments had found, it is crucial to build an electronic entity that was named egovernment, to make transactions easier for citizens, and to make government nearer to society. The objective of this study is to assess the extent of e-government application on different countries, particular in Jordan; in addition, several experiences were displayed in this study. The examination was qualitative through interviewing governmental employees for extracting results based on their answers, focusing on the continuity of using e-government by users as a dependent variable. The conclusion was that the policies are trending to build their egovernment entity, and to make it available for citizens to use. Further, this study recommends the government to concentrate on the path of building individuals' trust as well as using social influence to reinforce the idea of e-government service and evolve its usage.
\end{abstract} Jordan

Keywords-e-Government; citizens; governmental transactions;

\section{INTRODUCTION}

The improvement of ICT is quick as of now significantly affect human life. In the line with this development, the worldwide versatile Internet clients' infiltration has achieved 4.68 billion by 2019 [1]. In Jordan, for instance, the penetration rate has come to 83 percent. This provoked an adjustment in procedures, capacities, and approaches in various areas of human life be found on ICT, including open segment administrations.

Furthermore, Jordan has a tremendous successfully mounting in telecommunication industry in the recent years. The Central Bank of Jordan was launched an electronic program so-called (E-fawateercom) since 2015 [2]. This program has some important benefits such as reduce the time, money and effort of paying bills compared to the traditional way.

Government aspects have also changed, including the departments by providing public service oriented to satisfy most people [3]. As a result, these Changes in the general society division are described by the improvement of electronic government or supposed e-government. In general, this study suggests dimensions of the most critical aspects towards the individual's choice to utilize e-government services in Jordan.

\section{The Aspect OF E-GOVERnMEnt Structure}

Governments are always searching to save costs in providing services chiefly along with the economic crisis existences. In this line, e-government possesses vital benefits to developing nations such as citizen empowerment by offering them with a variety of options online channels to improve the quality of service delivery [4]. A review of present literature exposes that Jordan has been heavily investing in enhancing its e-government facilities to the community.

E-government is planned the procedure of cooperation among government as well as society. According to [5], one critical aspect in the execution of e-government administrations is the acknowledgment and the readiness of society to utilize e-government administrations. From citizens' viewpoint, e-government allows persons to access public services to do their government transactions in a convenient way at anytime from anywhere.

E-government is an innovative form of advanced technology, with a series of set processes that the citizens' $\operatorname{logs}$ into the website by using a private username and password based on their selection and secret key with the end goal to do their various online transactions. An outline of the design of the e-government is illustrated in Fig. 1, which links to the essential beneficial components and their jobs inside the framework. Connection among citizens and specialist system for government frameworks is upheld by staggered exchanges.

Furthermore, the e-government framework bolsters correspondence with different servers, for example, Internet servers support the service administrations offering to clients. In turn, the (SWAN) provides secured as well as high-speed connectivity for Government operation between connecting State Headquarters and District Headquarters. The egovernment framework bolsters correspondence with different servers, for example, Internet servers to support the service administrations offering to clients. In turn, the (SWAN) provides secured and high-speed connectivity for Government functioning between connecting State Headquarters and District Headquarters. 


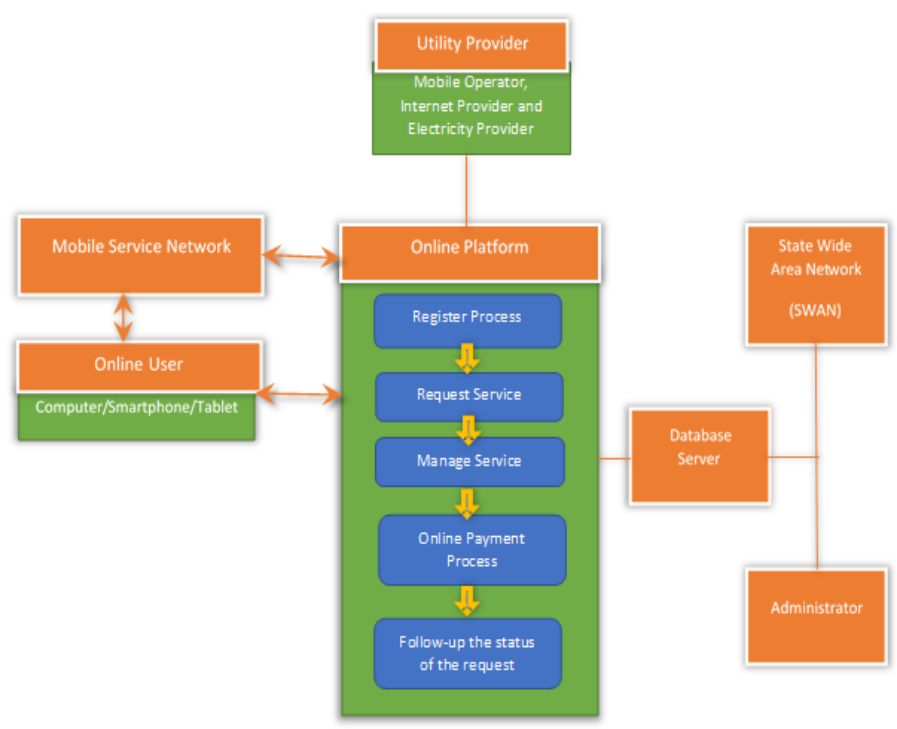

Fig. 1. e-Government Architecture.

In light of the data above, it very well may be seen that the network turns into a vital piece of the working of egovernment, the cooperation between the national administration and the network can function admirably if there is investment from general society. In the event that there is lack of interest of the public in embracing e-government, it will never function and being vain presence.

One of the researcher's expresses that more consideration has been compensated to e-government administrations received from the point of view of the "supply" [6]. Then, simply little the researchers have been investigated for the civilian request's [7], and preparation [8]. The shortcoming of the investigations above does not possess a solid establishment to give a calculated model of the e-government benefit for a developing nation.

In [9] has portrayed e-government as the strategy for governments to use the many imaginative data innovation, for example, online web application. Such applications may outfit the citizens, inside associations with progressively accommodating obtainment to government, upgrade great administration, and offer more opportunities to law grounded establishments and methods, incorporates numerous issues, for instance, trust, security, insurance, transparency, care, and quality.

In addition, several initiatives of e-government in advancing nations failed because there is a wide gap between the e-government design as well as exciting condition in upcoming republics, like inadequate information, communication, and technology management and infrastructure, resulting in low acceptance of the online services by people as well as businesses.

The advancement of innovation is developing with time. This empowers a great deal of changes in procedures, capacities, and arrangements in different business exercises or in the general population segment. Changes that happen in the general population segment is set apart by the improvement of electronic-government.
There are four sorts of orders, first, to be specific Citizens, Government (G-to-C), and the second one, to be specific Government to Business (G-to-B), Government to Government (G-to-G), and the last one in particular Government to Employees (G-to-E) [3,10]. G-to-C is an egovernment application that most popularly known. Whereby, the government here creates an expansive arrangement of data innovation with the fundamental target to reinforce cooperation with the citizens.

Many researches investigating what factors exist behind personal conduct towards choosing to utilize e-government services have been carried outside the Arab world. Thereupon, this research comes to assess the extent of e-government empowerment in different public sectors in Jordan, having into the picture of critical factors that may increase the dependence on e-government within the Jordanian community.

\section{RELATED WORK}

The study of [8] revealed that an efficient e-government program needs a coherent set of strategies and policies to control the establishment of information systems, technical infrastructures, and the essential regulatory frameworks. Egovernment success is highly reliant on the strategies, which are incorporated into the perspective of various levels of the society. There is a lack of consensus within the literature regarding the significance of approach for e-government adoption [6]. Certain researches on e-readiness assessment tools emphasize that strategy of ICT is crucial for successful adoption of e-government [11]. While others hold that studies IT, approach does not possess a strong effect on e-government readiness [17]. Nevertheless, these findings as well as ereadiness evaluation tools consider the policy as the strategy of e-government not as administration organizational ICT approach. Scholars refer the portal as "a program of service transformation" since it serves as the umbrella for entire government administrations, authorities and departments [16].

The e-government program from the viewpoint of [19] can result in improved government effectiveness and efficiency in delivering proper services to different sectors of consumers via numerous delivery channels. What's more, there exist three e-government portal complication levels that are transactions concerning incorporation of numerous organizations, single organization transactions, and information distributing as well as connecting of present web sites.

\section{Methodology}

This study adopted qualitative research to adopt the strategy of in-depth focus interviewing employees working in different sectors of the governmental institutions. This research approach was chosen since it was suitable in obtaining detailed information concerning opinions, perceptions, and personal feelings on this topic. This research design allows collections of perceptions about e-government convenience process. The selection of the interviewees was based upon their willingness to participate from different sectors in Jordan such as: health, tele-communication companies, a social security, Jordan electricity company, municipality, and traffic department. 
A pre-structured interview was done to assess the dependent variable that is going to be analyzed is the continuity of using e-government. This was conducted in a pleasant atmosphere. Other independent variables are going to be analyzed to see its effect on the dependent variable. These dependent variables are the government readiness to apply egovernment for a hand, and on the other hand the citizen willingness to utilize e-government application with the cons and pros of using this application on both parties, the government and the citizens.

All questions were concerned with the e-government issues, like its benefits and online information privacy and security. Furthermore, the interviewees were also stimulated to make comparisons between online as well as offline government convenience. The strength of this research is that it provides detailed evaluation of the resources, services, and agency. Also, it backs strategy formulation at agency level. Conversely, it does not offer details required for effective strategy formulation at different levels of governance like community and local levels, of multi-level governance.

\section{RESUlt AND Discussion}

Assessing 16 participants did the research from different governmental sectors as it was mentioned in the methodology. However, the sample size of the participants was small but adequate for qualitative methods, since the primary concern of this research is placed on the deriving of considerable data rather than the verification of hypotheses [11].The textual outcomes of the focus group interviews were content assessed by the authors of this study.

All the differences were solved through meeting to capture significant facets of e-government aspects. The interview was constituted from five questions that assessed the dependent and the independent factors; they are going to be discussed as follows.

\section{A. When do you Expect to Fully Rely on e-Government and the Traditional Paper Works Omitted?}

All of the interviewees had the opinion that fully turning toward e-government will be soon, in line with the Jordanian Government's policy towards digitizing the transactions. Some of them had the opinion that the e-government process had already started as the employee in the traffic department, municipality, tele-communication companies and the Jordan electricity have stated:

"Paper works in our field of work cannot be omitted, however, the application of e-government has started to be applied and a website with usernames is being used for different services such as tax records and invoice numbers."

While another participant stated that it needs more time, as the employee of health department stated:

"As it is obvious from the updates to the system, and the new applied program of visits which is under the test now, I expect that within one year, and maximum for two years. Paperwork will be limited and the whole information will be saved on the computers such as the medications exist at the pharmacies, the medical prescriptions of the patients, and booking time with their doctors, etc."
Based on the employees' opinion, the project of egovernment needs a short period may not exceed two years at their discretion.

\section{B. Do you Encourage the use of e-Government? And why?}

All of the participants encouraged the use of egovernment; each one gave his/her perspective depending on the nature of his/ her employment.

The employee in health department suggesting the issue of honesty as he declared that:

"The access of data will be easier and the ability of manipulation of the data and stocks of medicines and other gadgets will be limited. Everything will be present before each single person in the department, so the censorship will be more intense. Each employee will be doing his/her job sincerely, and each patient will take his/her right in having the most proper health care."

One of the participants from the social security, however, had her doubts about the application of e-government as she remembered some bad experiences with the connection to the web:

"Sometimes I feel that it is a good step forward, until the connection with the network is disconnected, or the system when it gets down and transactions are stopped until reconstruction is done, I feel that this is a quiet endangering. However, we all hope that every bad and good expectation is given into consideration and a sort of pro-activeness is applied to overcome a bad circumstance before it occurs."

Moreover, saving time with a high level of accuracy and less chances to do mistakes were the points, which were repeated by the rest of the participants.

\section{Do you Think that the Jordanian Society can Adopt e- Government in their Transactions?}

This question had variations in answers among different participants, some of them said that it is possible; others said that it is possible but some obstacles might face the users.

Different economic levels are present in the Jordanian Society, and the vast majority of them are classified as a low economic level families and members.

From the perspective of an employee works in health stated that adopting e-government might be not easy to the Jordanian society. While employee in the Jordanian Electricity Company and municipality focused on the idea of change and the presence of willing on the society to adopt new methods, with the presence of doubts and fears to use these new methods as she stated:

"Change is hard, and the Jordanian Society is known to be reluctant to any new practice that would make them adopt new methods and train on the way of using them, even if it would make their lives easier.

In addition, the culture of doubt is present in most of the members of the society; they will be hardly convinced that this step will be for their own benefit. They will be worried about their safety and privacy, and convincing them will be hard." 
From the side of tele-communication companies and traffic department were optimistic and believed that this awareness is spread to the members of the society. They also added:

"They can adopt e-government services; however, they will need to have an e-fawateercom account which needs to have a bank record which might be hard on some citizens"

\section{Do you Think that the Government has the Appropriate Infrastructure for such a Change?}

Most of them had the opinion that the government infrastructure is appropriate as a starting experience, however, it needs to be updated and more training to the employees is required. While one of the participants in the traffic department was very pleased regarding the government infrastructure, however, repairs are required based on the users' feedback as he stated:

"Yes and new gadgets are being spread to policemen to be directly linked to the net of traffic and vehicle departments' database. Based on this, we can say that the infrastructure is almost ready. He added that based on the feedback from users is the infrastructure needs to be updated continuously."

On the other hand, the view of employee in Communication Company was completely satisfied with the services of the e-government and the infrastructure of it as he stated:

"Yes, the system is working dynamically to be updated, to solve the problems that face users of the society. In addition, the government is trying to hire qualified employees with a good experience and a wide background in IT, so the hitches are going to be taken into consideration in advance."

\section{E. What are the Factors that Affect e-Government Adoption?}

After the analysis the factors can be separated into two groups, factors related to the government, and other factors related to the citizen.

The factors related to the government are dependent on the IT infrastructure and the employees' knowledge and willingness to follow-up and update it. While the factors related to the citizen are related to the economic situation of the citizen as well as the background and the culture of the families.

Table I summarizes forth the major dimensions of the critical facets of e-government derived from the results, and their associated descriptions.

Compared to our view of results, past researches about the selection of e-government has examined a few considers, for example, trust government, trust in web innovation, use of egovernment value-based administration and others as a major issue in most recent five years $[3,12,13]$. In view of the related works over, the creators supported that those variables have generally proposed superior information on various sorts of egovernment benefit from a few points of view.

In the meantime, previous research on e-government appropriation has for the most part centered on the developed nations; for example, learn concerning the acknowledgment as well as utilization of government Internet benefits in Netherland [14], a research focused on the client who uses egovernment in Belgium [15], and assessment of government e-charge sites in Sweden [16].

Prominently, only a couple of research examined the selection in developing nations, for example, learn regarding e-government reception in Cambodia [17], and surveying resident appropriation of e-government activities in Gambia [18]. In outcome, little consideration was gotten to analyze egovernment appropriation and utilize in the emergent nation as a rule.

Furthermore, [19] had focused on the application of egovernment in Saudi Arabia. The qualitative research done and a survey were both done to find the presence of success factors such as presence of software and technology that support using e-government, presence of customer service, the level of education as well as computer skills present upon users, the extent of access between users, the level of privacy presented to the users in addition to security, factors related to religion and culture, financial ability, and other factors which might include age and gender.

The findings of this research had shown that the issues of e-government application success are present, and it is showing a bright future, as there is an extent of acceptance among the Saudi population.

Parallel with the study of [20] had focused on the opinion of e-government upon Jordanian citizens, and it was found that the perception of using e-government in Jordan is well due to seeing helpfulness, usability, social impact, respond, and similarity, yet the cost of this service is one of the suppression aspects that negatively affect using e-government. Another study was done earlier by [21], had assessed the satisfaction of the users using an electronic survey. The study demonstrated the significance to uncover the key drivers of efulfillment in order to give criticism in many proposals that will empower making e-Government gateway which are perfect with the people' needs and desires.

TABLE. I. DIMENSIONS OF E-GOVERNMENT

\begin{tabular}{|l|l|}
\hline Dimensions & Description \\
\hline \multirow{3}{*}{ Perceived Usefulness } & $\begin{array}{l}\text { Check-out process } \\
\text { Payment method } \\
\text { Reducing cost } \\
\text { Saving time } \\
\text { Saving energy } \\
\text { Useful information }\end{array}$ \\
\hline \multirow{3}{*}{ Perceived Ease to Use } & $\begin{array}{l}\text { Easy navigation } \\
\text { Accessible anywhere } \\
\text { Accessible anytime }\end{array}$ \\
\hline Trust on Web & Personal data security \\
\hline \multirow{3}{*}{ Social Influences } & Word of mouth \\
& T.V. \\
\hline \multirow{2}{*}{ Radio Infrastructure } & Social media \\
\hline & Internet coverage \\
& Computers and Tablets \\
& Websites design \\
\hline
\end{tabular}




\section{CONCLUSION}

This study proposes dimensions of the most critical factors towards the individual's choice to utilize e-government services in Jordan. As so far, Jordan is going to follow the trend of adopting e-government, as it has positive effects on the quality of daily services transactions. In addition, spreading the awareness among the society members will encourage them to use this application.

In the end, the concept of e-government is constantly developing and changing to keep abreast of technological changes in term of designing and promoting services. In this context, there is an urgent necessity to find creative methods of evolving lasting beneficial services to fill gaps between service performance and people anticipations particularly in developing countries.

\section{FUTURE STUDIES}

The study needs to include more participants from different government sectors; in addition, it would give additional conclusions when citizens are included in the study. This study is not free of limitations, such as a qualitative technique is used in the study. Future studies therefore could use a quantitative study in seeking respondents' opinions. To put it plainly, A TAF model could be adopted to examine the most important factors affecting people's perception towards acceptance of e-government in Jordan.

\section{REFERENCES}

[1] Laith T. Khrais. Toward A Model For Examining The Technology Acceptance Factors In Utilization The Online Shopping System Within An Emerging Markets, 9 (11), 2018, 1099- 1110.

[2] Laith T. Khrais. The Impact Dimensions of Service Quality on the AcceptanceUsage of Internet Banking Information Systems, American Journal of applied sciences, 15(4), 2018, 240-250.

[3] Alzahrani L, Al-Karaghouli W, Weerakkody V. Analysing the critical factors influencing trust in e-government adoption from citizens' perspective: A systematic review and a conceptual framework. International Business Review. 2017 Feb 1;26(1):164-75.

[4] Kacem A, Belkaroui R, Jemal D, Ghorbel H, Faiz R, Abid IH. Towards improving e-government services using social media-based citizen's profile investigation. InProceedings of the 9th International Conference on Theory and Practice of Electronic Governance 2016, 187-190. ACM.

[5] Hashim HS, Hassan ZB, Hashim AS. Factors influence the adoption of cloud computing: A comprehensive review. International Journal of Education and Research. 2015;3(7):295-306.

[6] Al-Khatib H, Lee H, Suh C, Weerakkody V. E-government systems success and user acceptance in developing countries: The role of perceived support quality. 2019.
[7] Zejnullahu F, Baholli I. Overview of researches on the influential factors of m-government's adoption. European Journal of Management and Marketing Studies. 2017 Aug 11.

[8] Moon M. J., Welch, E., W. \& Wong, W. 2005. What Drives Global EGovernance? An Exploratory Study at a Macro Level. InProceedings of the 38th Hawaii International Conference on System Sciences. https://www.researchgate.net/publication/221179057_What_Drives_Glo bal_EGovernance_An_Exploratory_Study_at_a_Macro_Level Date of access 2017 Mar (Vol. 12).

[9] Majdalawi YK, Almarabeh T, Mohammad H, Quteshate W. Egovernment strategy and plans in Jordan. Journal of Software Engineering and Applications. 2015 Apr 14;8(04):211.

[10] Witarsyah D, Sjafrizal T, Fudzee MD, Farhan M, Salamat MA. The critical factors affecting e-government adoption in Indonesia: A conceptual framework. International Journal on Advanced Science, Engineering and Information Technology. 2017 Feb 22;7(1):160-7.

[11] Izogo EE, Jayawardhena C. Online shopping experience in an emerging e-retailing market: Towards a conceptual model. Journal of consumer Behaviour. 2018 Jul;17(4):379-92.

[12] Alam MZ, Hu W, Barua Z. Using the UTAUT model to determine factors affecting acceptance and use of mobile health (mHealth) services in Bangladesh. Journal of Studies in Social Sciences. 2018 Dec 1;17(2).

[13] AL-Hujran, O., AL-Debei, M. M., Chatfield, A. and Migdadi, M. The imperative of influencing citizen attitude toward e-government adoption and use. Computers in human Behavior,53(1), 2015,189-203.

[14] Wirtz BW, Piehler R, Rieger V, Daiser P. E-government portal information performance and the role of local community interest. Empirical support for a model of citizen perceptions. Public Administration Quarterly. 2016 Apr 1:48-83.

[15] Wirtz BW, Kurtz OT. Local e-government and user satisfaction with city portals-the citizens' service preference perspective. International Review on Public and Nonprofit Marketing. 2016 Oct 1;13(3):265-87.

[16] Arias MI, Maçada AC. Digital Government for E-Government Service Quality: a Literature Review. InProceedings of the 11th International Conference on Theory and Practice of Electronic Governance 2018 Apr 4 (pp. 7-17). ACM.

[17] Rana NP, Dwivedi YK, Williams MD. A meta-analysis of existing research on citizen adoption of e-government. Information Systems Frontiers. 2015 Jun 1;17(3):547-63.

[18] Jung D. " Assessing citizen adoption of e-government initiatives in Gambia: A validation of the technology acceptance model in information systems success". A critical article review, with questions to its publishers. Government Information Quarterly. 2019 Jan 1;36(1):5-7.

[19] Basahel, A. and Yamin, M. Measuring success of e-government of Saudi Arabia. International Journal of Information Technology, 9(1), 2017, 287-293.

[20] Abu-Shanab, E. and Haider, S. Major factors influencing the adoption of m-government in Jordan. Electronic Government. An International Journal, 11(1), 2015,223-240.

[21] Sachan A, Kumar R, Kumar R. Examining the impact of e-government service process on user satisfaction. Journal of Global Operations and Strategic Sourcing. 2018 Nov 19;11(3):321-36. 